\title{
Biologia e ecologia de Anthodioctes moratoi Urban (Hymenoptera, Megachilidae, Anthidiini) em matas contínuas e fragmentos na Amazônia Central, Brasil
}

\author{
Elder Ferreira Morato ${ }^{1}$
}

\begin{abstract}
Biology and ecology of Anthodioctes moratoi Urban (Hymenoptera, Megachilidae, Anthidiini) in continuous forests and forest fragments in Central Amazonia, Brazil. Anthodioctes moratoi Urban, 1999 was described based on specimens collected in the state of Amazonas during a study of the ecology of trap-nesting bees and wasps. Sampling was done between 1988 and 1990 north of Manaus, in areas of the "Forest Fragment Biological Dynamics Project". Wooden trap-nests were set in different heights inside continuous forests, forest fragments of different sizes, natural gaps inside continuous forest, and in cleared areas between forest fragments. A total of 61 nests were collected from which 33 males and 46 females emerged. The majority of nests was collected in continuous forests, at $15 \mathrm{~m}$ height, in holes $4.8 \mathrm{~mm}$ in diameter. No nest was collected in cleared areas. There was no correlation, neither between number of nests and monthly precipitation, nor between the monthly number of nests constructed in the two consecutive years. No nest was constructed between January and June 1989. Overall, this coincided with the period of least activity of other trap-nesting bees in the studied areas. The nests consisted of a linear series of brood cells with walls made of resinous material mixed with small wood chips. The average length of the provisioned cell was $13,4 \mathrm{~mm}$. Half of this length was occupied by a pollen mass. The number of provisioned cells varied between two and nine. In $52 \%$ of the nests there was brood mortality in at least one cell. The phorid fly Phalacrotophora (Omapanta) sp. was the only nest associate, emerged, from just one cell.

KEY WORDS. Anthidiini, Anthodioctes moratoi, Amazonia, bee biology, trap-nests
\end{abstract}

A tribo Anthidiini apresenta ampla distribuição geográfica, sendo representada tanto no Velho como no Novo Mundo. MiCHENER (1948) listou cerca de 22 gêneros de abelhas não-parasitas para esta tribo aos quais URBAN (1991, 1992, 1994, 1995a,b, 1996, 1997a,b) acrescentou vários outros e ROUBIK (1989) relacionou 62 gêneros para toda a região tropical.

Anthodioctes Holmberg, 1903 é endêmico da região neotropical (MICHENER 1948; GRISWOLD \& MiCHENER 1988). URBAN (1999) descreveu 19 espécies neste gênero, entre elas Anthodioctes moratoi, além de relacionar outras dezoito, descritas previamente por outros autores.

Várias espécies de Anthidiini fazem seus ninhos em cavidades preexistentes na madeira ou no solo e podem, ou não, usar resina na construção das paredes das células (MicheNer 1948; JAYCOX 1967; KROMBEIN 1967; ARMBRUSTER 1984; PARKER 1987; CAMILlo et al. 1995; MORATO \& CAMPOS 2000). Existem diferenças entre os gêneros, em relação ao hábito de nidificação (MICHENER 1948). Por exemplo, Trachusa Panzer, 1804 (considerado o mais "primitivo") e Heteranthi-

1) Departamento de Ciências da Natureza, Universidade Federal do Acre. 69915-900 Rio Branco, Acre, Brasil. 
dium Cockerell, 1904 constróem cavidades no solo e nelas nidificam. Usam resina na construção das paredes das células, a qual pode ser misturada com pedaços de folhas ou com o próprio solo. Anthidium Fabricius, 1804 e Callanthidium Cockerell, 1925 nidificam em cavidades feitas por outros insetos no solo, mas não usam resina. Em Dianthidium Cockerell, 1900 os ninhos podem ser expostos ou feitos no interior de conchas de moluscos ou em pequenas cavidades. As células são construídas com resina misturada a pedrinhas. Anthidiellum Cockerell, 1904 constrói ninhos expostos e as paredes das células são finas e de resina, com pouco ou nenhum outro material misturado.

Existem poucas informações sobre a biologia das espécies neotropicais de Anthidiinae. LAROCA \& ROSADO NETO (1975) fornecem informações sobre fontes de alimento, comportamento de cópula dos adultos e estrutura dos ninhos de Hypanthidioides arenaria (Ducke, 1907) [= Dicranthidium arenarium] coletados no interior do Maranhão. Dentre os ninhos de abelhas solitárias coletados, através de ninhos-armadilhas, por CAMILLO et al. (1995) em um estudo realizado no interior de São Paulo, quatro foram provisionados por duas espécies não identificadas de Anthodioctes Holmberg, 1903.

Os dados apresentados neste trabalho foram obtidos como parte de um estudo mais amplo sobre os efeitos da fragmentação de florestas tropicais sobre as comunidades de abelhas e vespas solitárias que nidificam em cavidades preexistentes (Morato \& CAMPos 2000); "Projeto Dinâmica Biológica de Fragmentos Florestais - PDBFF" (convênio INPA/WWF/STRI - Instituto Nacional de Pesquisas da Amazônia/World Wildlife Fund/Smithsonian Tropical Research Institution) (LoVEJOY et al. 1986). Neste projeto, foram coletados ninhos de uma espécie nova de Anthidiini, posteriormente descrita (URBAN 1999).

Este trabalho tem como objetivo relatar os dados disponíveis sobre $A$. moratoi.

\section{MATERIAL E MÉTODOS}

As coletas foram realizadas na Amazônia Central, em uma região situada aproximadamente entre 70 a $90 \mathrm{~km}$ ao norte de Manaus, Amazonas ( $2^{\circ} 30^{\prime} \mathrm{S}$ e $\left.60^{\circ} \mathrm{W}\right)$, e entre 100 a $150 \mathrm{~m}$ de altitude, nas áreas de trabalho do PDBFF, convênio INPA/WWF/STRI, entre junho de 1988 e junho de 1990.

A região apresenta vegetação típica de floresta tropical úmida de terra firme, com dossel atingindo em média 30-37 $\mathrm{m}$ de altura. A precipitação média anual é de $2.186 \mathrm{~mm}$, com uma estação mais seca entre julho e setembro, quando pode ser menor que $100 \mathrm{~mm}$ por mês (BIERREGAARD \& LOVEJOY 1988).

As coletas foram realizadas em dois fragmentos de mata nativa de 1 ha, dois fragmentos de 10 ha, um fragmento de 100 ha, sete locais de mata contínua e em 22 clareiras naturais situadas em seu interior. Ao longo deste texto, a expressão mata contínua será usada como sinônimo de floresta primária, não-fragmentada e nãoperturbada.

Também foram feitas amostragens em duas áreas onde a floresta primária foi derrubada, situadas próximas dos fragmentos isolados, uma delas ocupada por 
pastagem e vegetação secundária com várias espécies de espécies ruderais. A outra, por vegetação secundária muito desenvolvida e fechada (capoeira), com forte dominância de espécies de Cecropia Loefl. (Cecropiaceae).

Ninhos de abelhas foram coletados, quinzenalmente, através da técnica de ninhos-armadilhas (KROMBEIN 1967). Foram usadas peças de madeira com cavidades de $8 \mathrm{~cm}$ de comprimento por 4,8; 9,5 e 12,7 mm de diâmetro. Blocos dessas peças foram instalados nas áreas de florestas, em árvores, nas alturas de 1,5; 8 e 15 $\mathrm{m}$, e nas áreas desmatadas a $1,5 \mathrm{~m}$ apenas.

Na maioria dos ambientes amostrados foram instalados 216 ninhos armadilhas. Em outros, esse número foi menor. Assim, na análise dos dados, o número de ninhos coletado em cada ambiente foi dividido pelo número de peças instaladas (esforço amostral). Uma descrição mais detalhada da área de estudo e do método de amostragem encontram-se em MORATO \& CAMPOS (2000).

Os exemplares adultos foram identificados pela Dra. Danúncia Urban do Dep. de Zoologia da Universidade Federal do Paraná. Parte do material encontra-se depositado naquela instituição e parte na Coleção do Museu Regional de Entomologia do Departamento de Biologia Animal da Universidade Federal de Viçosa.

\section{RESULTADOS}

Foram coletados, ao todo, 61 ninhos de A. moratoi, dos quais, cerca de $75 \%$ em mata contínua. Nenhum ninho foi coletado nas áreas de derrubada. A figura 1 mostra o número de ninhos coletados nos diferentes ambientes corrigido pelo esforço amostral. Emergiram, dos ninhos, 79 indivíduos (33 fêmeas e 46 machos), variando de um a oito por ninho.

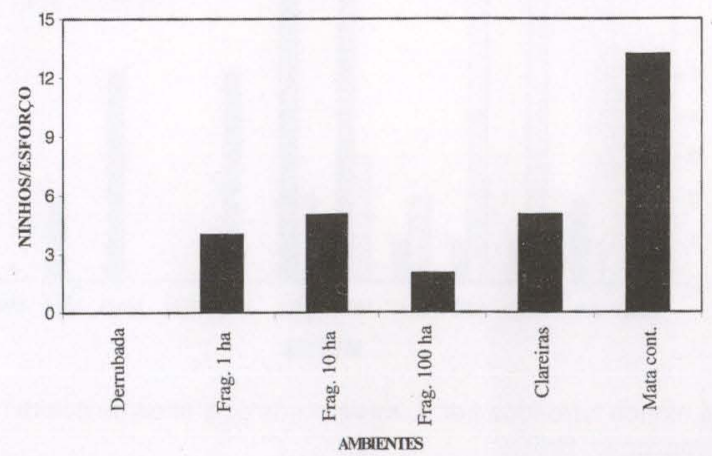

Fig. 1. Número de ninhos, corrigido pelo esforço de amostragem, de A. moratoi coletados em diferentes ambientes do PDBFF, Amazonas, Brasil.

O número de nidificação em diferentes alturas na mata contínua e fragmentos é mostrado na figura 2. Mais ninhos foram coletados em ninhos-armadilhas instalados a $15 \mathrm{~m}$ de altura $\left(X^{2}=21,4 ; \mathrm{p}<0,0001\right)$.

Cerca de $92 \%$ dos ninhos foram fundados em ninhos-armadilhas com cavidades com diâmetro igual a $4,8 \mathrm{~mm}$. 


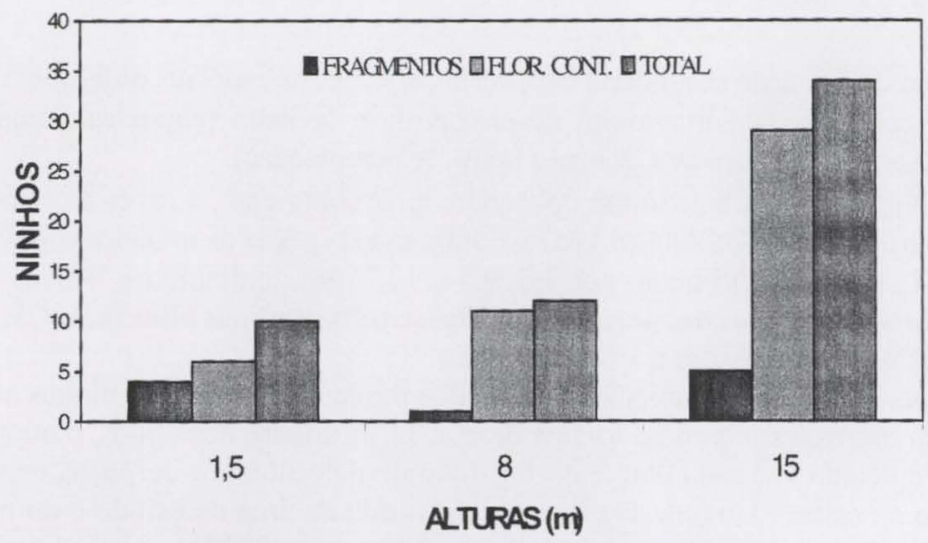

Fig. 2. Número de ninhos de $A$. moratoi coletados em diferentes alturas em fragmentos de floresta e mata contínua, Amazonas, Brasil.

O número de ninhos fundados nos dois anos (junho de 1988 a junho de 1990) de amostragem é mostrado na figura 3. Em ambos os anos não foi coletado nenhum ninho nos meses de junho, fevereiro e maio. Não houve correlação entre os dois anos, em relação à fundação de ninhos ao longo dos meses $\left(r_{\mathrm{s}}=0,22 ; \mathrm{p}>0,05\right)$. Também não houve correlação entre o número de ninhos e a precipitação, ao longo dos meses ( $\left.r_{\mathrm{s}}=-0,24 ; p>0,05\right)$ (Fig. 4).

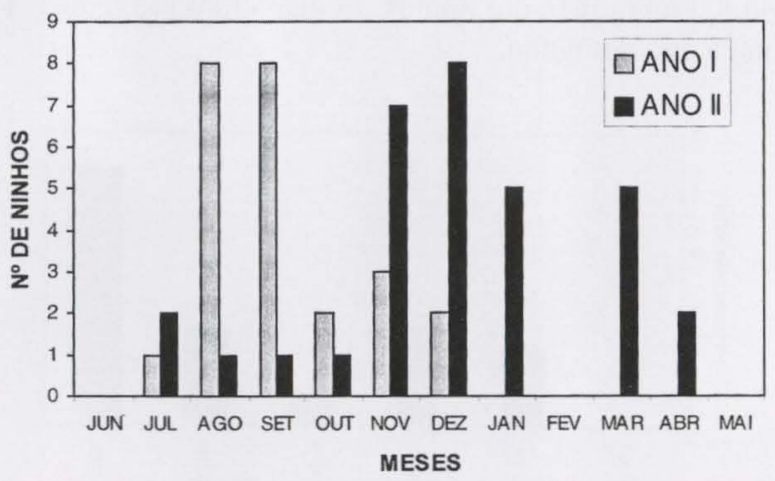

Fig. 3. Número de ninhos fundados por A. moratoi nos dois anos de coleta (junho de 1988 a junho de 1990), Amazonas, Brasil.

Os ninhos de A. moratoi são constituídos por uma série linear de células cujas paredes são de uma resina vegetal muito viscosa misturada com fragmentos de madeira muito pequenos. O número de células provisionadas variou entre dois a nove. Não foram observadas células intercalares. Contudo, em três ninhos foram observadas células vazias (vestibulares) $(8,22$ e $56 \mathrm{~mm}$ de comprimento) no final da série de células provisionadas. Ao final dessas havia um tampão de fechamento de resina. O comprimento interno médio das células provisionadas foi igual a 13,4 


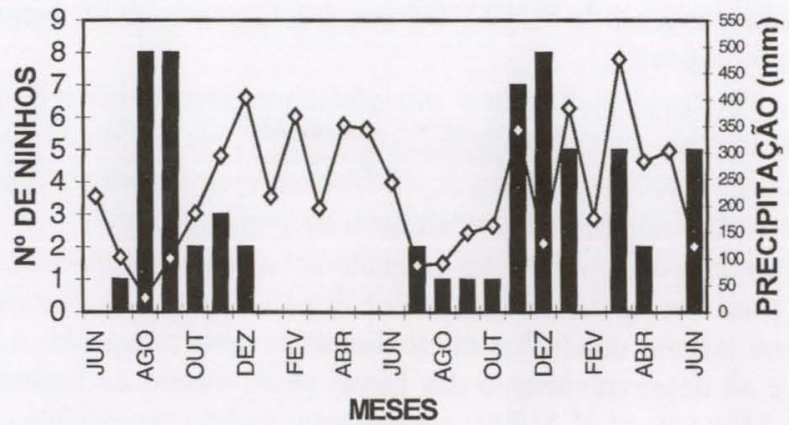

Fig. 4. Número de ninhos fundados e precipitação, ao longo dos meses, entre junho de 1988 e junho de 1990, Amazonas, Brasil.

$\mathrm{mm}(\mathrm{s}= \pm 3,4 ; \mathrm{n}=47)$. Metade desse espaço era ocupado por uma massa de pólen sobre a qual encontravam-se os ovos ou larvas. Em um ninho com seis células provisionadas foi observado na última um ovo na massa de alimento e nas anteriores, larvas em alimentação. Todos os demais ninhos abertos apresentavam apenas larvas em alimentação.

Em cerca de $52 \%$ dos ninhos houve mortalidade dos imaturos em, pelo menos, uma célula. Em uma única célula foi constatada a emergência de um parasita Phalacrotophora (Omapanta) sp. (Diptera: Phoridae). O ninho do qual emergiu esse parasita foi fundado em uma cavidade de $4,8 \mathrm{~mm}$ de diâmetro e foi coletado em 29.VII.1989 a $15 \mathrm{~m}$ de altura em um fragmento de floresta de 10 ha. Dele emergiram cinco abelhas (duas fêmeas e três machos). Embora, não quantificado, a ocorrência de fungos nos ninhos constituiu outro fator de mortalidade.

\section{DISCUSSÃO}

A maioria dos ninhos de A. moratoi foi coletada em ambientes de floresta primária. Isso sugere que esta espécie possa ser sensivel ao desmatamento e fragmentação. Durante os dois anos de amostragem nenhum ninho foi coletado na área de pastagem ou de capoeira.

Uma outra espécie de Anthodioctes, A. manauara Urban, 1999 também foi coletada pelo autor em um ninho obtido na floresta primária contínua. Um único indivíduo, macho, emergiu de uma célula provisionada no interior da cavidade de um ninho de barro abandonado de vespa solitária, de forma cilíndrica e com aproximadamente 2-3 cm de comprimento por $1 \mathrm{~cm}$ de diâmetro, localizado a cerca de $3,1 \mathrm{~m}$ do chão sobre a nervura central da parte abaxial da folha de uma palmeira acaule típica do sub-bosque, possivelmente do gênero Astrocaryum G. Mey (HENDERSON et al. 1995). O ninho foi coletado em 24.IX.1988 e, o adulto de $A$. manauara emergiu em 14.X.1988. O comportamento de nidificação no interior de ninhos de vespas parece ser comum em alguns Anthidiini. LAROCA \& ROSADO NETO (1975) coletaram ninhos de $H$. arenaria no interior de ninhos de barro abandonados de vespas Eumenidae. 
Ninhos de duas espécies de Duckeanthidium Moure \& Hurd, 1960 também foram coletadas nas áreas do PDBFF (MORATO \& CAMPOS 2000). Nenhum em área de pastagem ou capoeira.

Neste estudo, os ninhos de $A$. moratoi representaram cerca de $15 \%$ do total de ninhos de abelhas coletados nas áreas do PDBFF. No estudo de CAMILLO et al. (1995), os ninhos das duas espécies de Anthodioctes representaram apenas 0,2\% do total, apesar do maior tempo de amostragem do segundo estudo.

Maior número de ninhos foi coletado em armadilhas instaladas a $15 \mathrm{~m}$ de altura. Isso pode ser devido a uma maior disponibilidade de alimento, sítios de nidificação ou mesmo condições microclimáticas mais adequadas à atividade de nidificação e ao desenvolvimento das larvas nesse estrato da floresta do que no sub-bosque. Morato et al. (1999) encontraram padrão semelhante para espécies de Centris Fabricius, 1804 (Apidae, Centridini). Segundo RoubIK (1989, 1993) contudo, parece não haver uma forte associação, nas florestas tropicais, entre estrato vertical de nidificação e altura de forrageamento para várias espécies de abelhas.

Entre janeiro e junho de 1989 não foi coletado nenhum ninho de A. moratoi, o que coincidiu também com o período de menor atividade de nidificação de outras abelhas nos ninhos-armadilhas nas áreas estudadas (Morato, dados não-publicados). A pequena amostragem impede uma conclusão mais geral sobre sazonalidade. Porém, parece que $A$. moratoi ocorre o ano todo nos ambientes estudados.

A. moratoi utiliza resina na construção das células tal como ocorre em outras espécies de Anthidiini que nidificam em cavidades preexistentes na madeira (KROMBEIN 1967). A presença de células vazias no final da seqüência de células provisionadas observada em três ninhos, também foi relatada em ninhos de Dianthidium floridiense Schwarz, 1926, D. platyurum platyurum Cockerell, 1923 e D. ulkei perterritum Cockerell, 1913 por KROMBEIN (1967).

A mortalidade elevada dos imaturos deve ter sido conseqüência de manuseio inadequado dos ninhos, que foram transportados para o laboratório em Manaus. Embora não quantificada, mortalidade decorrente de ataque de fungos também ocorreu. PARKER (1987) relata mortalidade por ataque de fungo em um ninho de Callanthidium illustre (Cresson, 1879).

Várias espécies de insetos cleptoparasitas e parasitóides de Hymenoptera, Coleoptera e Diptera têm sido observados em ninhos de espécies de Anthidiini (HuRd \& Linsley 1950; KROMBEIN 1967; PARKER 1987; ROUBIK 1989). Dentre os Diptera foi relatada a ocorrência de Bombyliidae (HURD \& LinSLEY 1950; Krombein 1967) e Sarcophagidae (Hurd \& LinSley 1950). Contudo, Phalacrotophora (Omapanta) sp. foi o único inseto parasita que emergiu dos ninhos de $A$. moratoi. As espécies desse gênero são endoparasitas de larvas de Coccinellidae na Grã-Bretanha (COLYER 1952). Adultos desta espécie foram também obtidos de um ninho de Megachile orbiculata Mitchel, 1929 e de ninhos de vespas da familia Sphecidae nas áreas do projeto PDBFF (Morato, dados não-publicados).

AGRADECIMENTOS. À Dra. Danúncia Urban (Universidade Federal do Paraná) pela identificação das abelhas. Ao Dr. Forbes Peter Benton (então do Museu de Zoologia da Universidade 
de São Paulo) pela identificação do exemplar de Phalacrotophora sp. Este estudo foi parcialmente financiado pelo Instituto Nacional de Pesquisas da Amazônia (INPA) e pelo Smithsonian Tropical Research Institution (STRI) e representa a publicação número 354 da série técnica do projeto Dinâmica Biológica de Fragmentos Florestais.

\section{REFERÊNCIAS BIBLIOGRÁFICAS}

ARMBRUSTER, W.S. 1984. The role of resin in angiosperm pollination: ecological and chemical considerations. Amer. Jour. Bot. 71 (8): 1149-1160.

BierRegaARD JR., R.D. \& T. Lovejoy. 1988. Birds in Amazonian forest fragments: effects of insularization, p. 1564-1579. In: H. Quellet (Ed.). Acta XIX Cong. Int. Ornith. Ottawa, Univ. Ottawa Press, $1409 \mathrm{p}$.

Camil.lo, E.; C.A. Garófalo; J.C. Serrano \& G. Muccillo. 1995. Diversidade e abundância sazonal de abelhas e vespas solitárias em ninhos-armadilhas (Hymenoptera, Apocrita, Aculeata). Revta bras. Ent. 39 (2): 459-470.

Colyer, C.N. 1952. Notes on the life-histories of the British species of Phalacrotophora Enderlein (Dipt., Phoridae). Entomologist's Monthly Magazine 88: 135-139.

Griswold, T.L. \& C.D. Michener. 1988. Taxonomic observations on Anthidiini of the Western Hemisphere (Hymenoptera: Megachilidae). Jour. Kansas Entomol. Soc. 61 (1): 22-45.

Henderson, A.; G. Galeano \& R. Bernal. 1995. Field guide to the palms of the Americas. New Jersey, Princeton Univ. Press, 353p.

HURD JR., P.D. \& E.G. LinSLEY. 1950. Some insects associated with nests of Dianthidium dubium dilectum Timberlake, with a list of the recorded parasites and inquilines of Dianthidium in North America. Jour. N.Y. Entomol. Soc. 58: 247-250.

JAYCoX, E.R. 1967. An adventive Anthidium in New York State (Hymenoptera: Megachilidae). Jour. Kansas Entomol. Soc. 40 (3): 124-126.

Kromibin, K.V. 1967. Trap-nesting wasps and bees: life histories, nests and associates. Washington, D.C., Smithsonian Press, 569p.

LARocA, S. \& G.H. RosAdo Neto. 1975. Notas bionômicas: Hypanthidioides arenaria (Hymenoptera, Apoidea). Rev. Brasil. Biol. 35 (4): 847-853.

Lovejoy, T.E.; R.O. BierregaArd Jr.; A.B. Rylands; J.R. Malcon; C.E. Quintela; L. Harper; K.S. Brown JR.; A.H. POWELl; G.V.N. Powell; H.O.R. SCIIUBART \& M.B. HAYS. 1986. Edge and other effects on isolation on Amazon forest fragments, p. 257-285. In: M.E. Soul.E (Ed.). Conservation biology: the science of scarcity and diversity. Sunderland, Sinauer, 584p.

MiCuENER, C.D. 1948. The generic classification of the anthidiine bees (Hymenoptera, Megachilidae). Amer. Mus. Novitates 1381: 1-29.

Morato, E.F.; M.V.B. Garcia \& L.A. DE O. Campos. 1999. Biologia de Centris Fabricius (Hymenoptera, Anthophoridae, Centridini) em matas contínuas e fragmentos na Amazônia Central. Revta bras. Zool. 16 (4): 1213-1222.

Morato, E.F. \& L.A. DE O. CAMPOS. 2000. Efeitos da fragmentação florestal sobre vespas e abelhas solitárias em uma área da Amazônia Central. Revta bras. Zool. 17 (2): 429-444.

PARKER, F.D. 1987. Nests of Callanthidium from block traps (Hymenoptera: Megachilidae). Pan-Pacific Entomol. 63 (2): 125-129.

RouBIK, D.W. 1989. Ecology and natural history of tropical bees. Cambridge, Cambridge Univ. Press, $514 \mathrm{p}$.

. 1993. Tropical pollinators in the canopy and understory: field data and theory for stratum "preferences". Jour. Ins. Behav. 6 (6): 659-673.

Urban, D. 1991. Ctenanthidium, gen.n. de Dianthidiini com quatro espécies novas da América do Sul (Hymenoptera, Megachilidae). Revta bras. Zool. 8 (1/2/3/4): 85-93.

- 1992. Gnathanthidium, gen.n. de Anthidiinae da América do Sul (Hymenoptera, Megachilidae). Revta bras. Zool. 9 (3/4): 337-343. 
1994. Tylanthidium, gen.n. de Anthidiinae da América do Sul (Hymenoptera, Megachilidae) e nota taxonômica. Revta bras. Zool. 12 (2): 277-281.

. 1995a. Moureanthidium, gen.n. de Dianthidiini do Brasil (Hymenoptera, Megachilidae).

Revta bras. Zool. 12 (1): 37-45.

. 1995b. Grafanthidium, gen.n. de Dianthidiini do Brasil e uma espécie nova de Duckeanthidium Moure \& Hurd (Hymenoptera, Megachilidae). Revta bras. Zool. 12 (2): 435-443.

. 1996. Mielkeanthidium, gen.n. de Dianthidiini da América do Sul (Hymenoptera, Megachilidae). Revta bras. Zool. 13 (1): 121-125.

1997a. Chrisanthidium, um novo gênero sulamericano de Dianthidiini (Hymenoptera, Megachilidae). Revta bras. Zool. 14 (1): 181-185.

1997b. Larocanthidium gen.n. de Anthidiinae do Brasil (Hymenoptera, Megachilidae).

Revta bras. Zool. 14 (2): 299-317.

1999. Espécies novas e notas sobre Anthodioctes Holmberg (Hymenoptera, Apoidea,

Megachilidae). Revta bras. Zool. 16 (Supl. 1): 135-169.

Recebido em 21.IX.2000; aceito em 18.VII.2001. 